\title{
Knowledge and Awareness of Antibiotic Resistance Among Dental Students-A Questionnaire Based Study
}

ISSN: 2637-7764

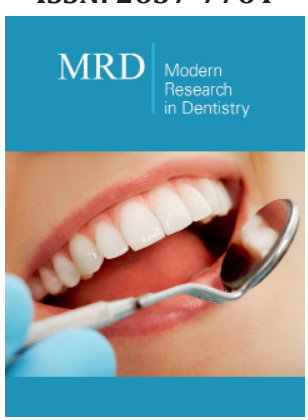

*Corresponding author: Smriti Jagdhari Golhar, C/O Dr. Anil Golhar, 256 Ramdaspeth, Nagpur Maharashtra, India

Submission: 侮 May 27, 2021

Published: 制August 03, 2021

Volume 6 - Issue 4

How to cite this article: Smriti Jagdhari Golhar,Mukta Motwani,SurbhiPatil,Shivani Shembalkar. Knowledge and Awareness of Antibiotic Resistance Among Dental Students-A Questionnaire Based Study. Mod Res Dent. 6(4). MRD. 000644. 2021. DOI: 10.31031/MRD.2021.06.000644

Copyright@ Smriti Jagdhari Golhar, This article is distributed under the terms of the Creative Commons Attribution 4.0 International License, which permits unrestricted use and redistribution provided that the original author and source are credited.
Smriti Jagdhari Golhar ${ }^{1 *}$, Mukta Motwani ${ }^{2}$, Surbhi Patil ${ }^{3}$ and Shivani Shembalkar ${ }^{3}$

${ }^{1}$ Sr. Lecturer Department of Oral Medicine and Radiology, VSPMS' Dental College, Nagpur, Maharashtra, India

${ }^{2}$ Professor and HOD, Department of Oral Medicine and Radiology, VSPMS' Dental College, Nagpur, Maharashtra, India

${ }^{3}$ VSPMS' Dental College, Nagpur, Maharashtra, India

\section{Abstract}

Aim: Knowledge and awareness of antibiotic resistance among dental students-A questionnaire-based study.

Material and Method: A cross sectional study was conducted to assess the knowledge of antibiotic resistance amongst dental students. An online questionnaire containing 11 questions was given to final year BDS students of VSPM Dental College, Nagpur. 85 students took part in the survey.

Result: $94.12 \%$ students knew about antibiotic resistance. $43.53 \%$ of students took antibiotics without prescription. $56.47 \%$ of students responded by saying that they stopped consuming antibiotics once the symptoms subsided.

Conclusion: Educational seminars must be conducted to improve student's knowledge on antibiotic resistance, its causes, prevention and side effects.

Keywords: Students; Antibiotics; Knowledge

\section{Introduction}

Antibiotics are types of antibacterial agents which are used in treatment and prevention of bacterial infections. Either they may kill, or they inhibit the growth of bacteria. Therefore, they are essential part in both prophylactic and as treatment modalities in documented as well as suspected infections [1]. In dental practice, mostly antibiotics are given after oral surgical and periodontal procedures, so it considered as lifesaving drugs. However, it also has some unfavourable side effects ranging from gastrointestinal disturbances to fatal anaphylactic shock.

Inappropriate, indiscriminate use of antibiotics has led to the development of antibiotic resistance. Epidemiological studies have demonstrated that there is a direct relationship between antibiotic consumption and the emergence and dissemination of resistant bacteria strains [1]. Resistance can also occur spontaneously through mutation [2]. Despite warnings regarding overuse, antibiotics are overprescribed worldwide [1,3,4]. A trend of indulging in self-medication has also been noticed among the educated population of some developing countries such as India [3]. There are multiple studies carried out across the world that have shown that antibiotics are not used prudently for various dental infections, and it has led to multiple complications including development of resistance. Considering this scenario, it is high time to create awareness, and to fill the gap about different dimensions of antibiotic uses. It is particularly as important to share this knowledge with the budding. Therefore, in this study, evaluation of knowledge, attitude and practice among dental students towards use of antibiotics was carried out. 


\section{Material and Methods}

The study was a cross-sectional survey. A questionnaire was prepared in English that contained questions about antibiotics, antibiotics resistance, its causes, prevention and its side effects. The questionnaire contained 11 questions and was distributed among 85 dental students of Final year, studying at VSPM Dental College and Hospital. The questionnaire was distributed online. The data was collected, tabulated and statistically analyzed.

\section{Result}

78.8\% student knew about antibiotics by definition (Figure 1). $36.5 \%$ repeated the same antibiotics for the next time using previous prescription (Figure 2). 43.5\% consumed antibiotics without prescription (Figure 3). $71.8 \%$ completed the prescribed antibiotics dose (Figure 4). 36.9\% stopped consuming antibiotics once the symptoms subside (Figure 5). 22.4\% think that antibiotics can be taken during viral infection (Figure 6). 94.1\% (Figure 7) knew about antibiotic resistance of which $71.8 \%$ think it is due to over usage as well as incomplete antibiotic course (Figure 8). 56.5\% knew about prevention of antibiotic resistance (Figure 9). 49.4\% knew about the side effects of antibiotic consumption (Figure 10). 87.1\% showed interest in attending seminars based on awareness about antibiotic and its resistance (Figure 11).

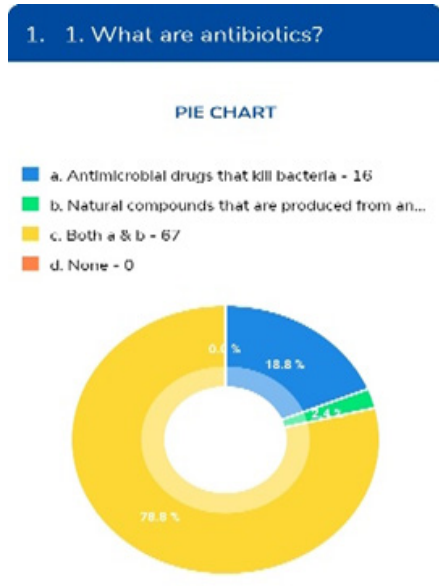

Figure 1: What are antibiotics?
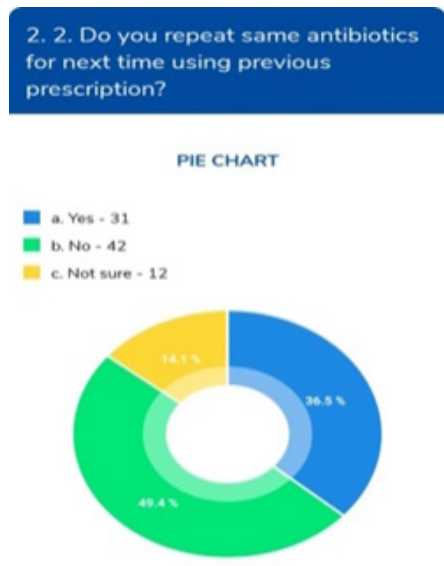

Figure 2: Do you repeat same antibiotics for next time using previous prescription?
3. 3. Do you ever consume

antibiotics without prescription?

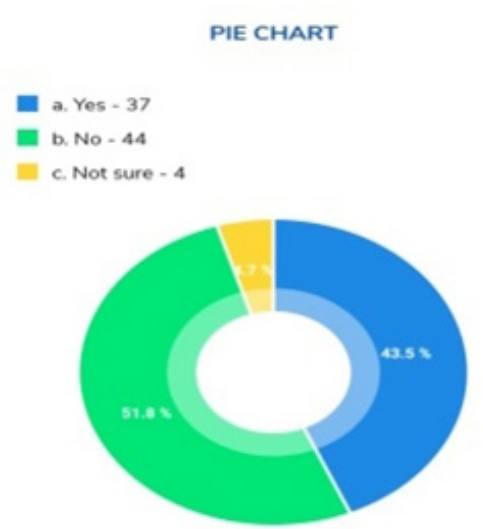

Figure 3: Do you ever consume antibiotics without prescription?

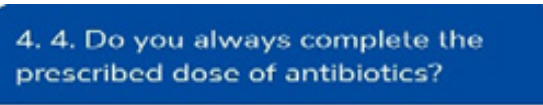

PIE CHART

$$
\begin{aligned}
& \text { a Yos - } 61 \\
& \text { b. No- } 16 \\
& \text { C. Not sure - } 9
\end{aligned}
$$

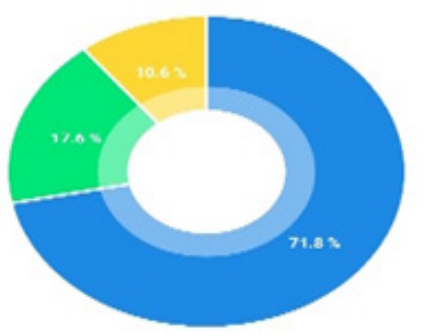

Figure 4: Do you always complete the prescribed dose of antibiotics?

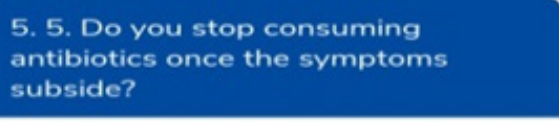

PIE CHART

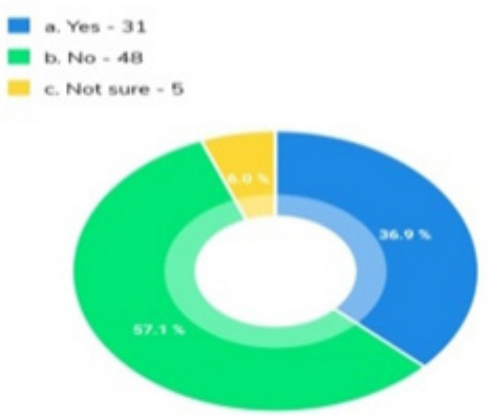

Figure 5: Do you stop consuming antibiotics once the symptoms subside? 
6. 6. Do you think antibiotics should

be taken during viral infections?

\section{PIE CHART}
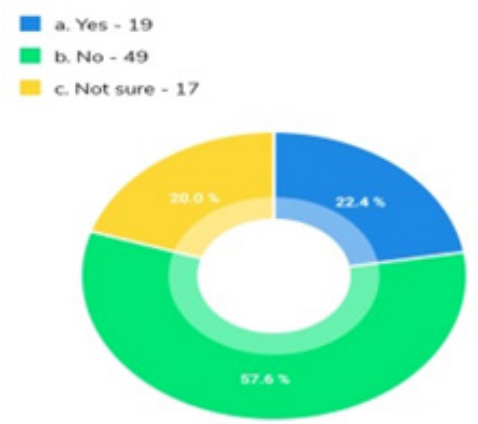

Figure 6: Do you think antibiotics should be taken during viral infections?

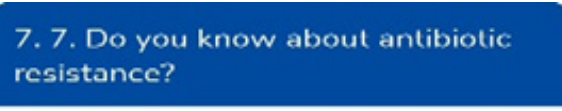

\section{PIE CHART}
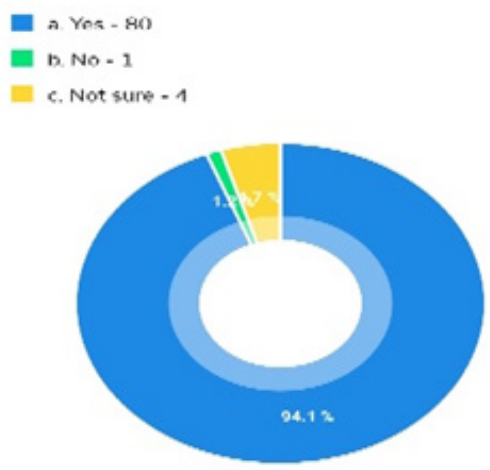

Figure 7: Do you know about antibiotic resistance?

8. 8. Do you know the cause of antibiotic resistance?

PIE CHART
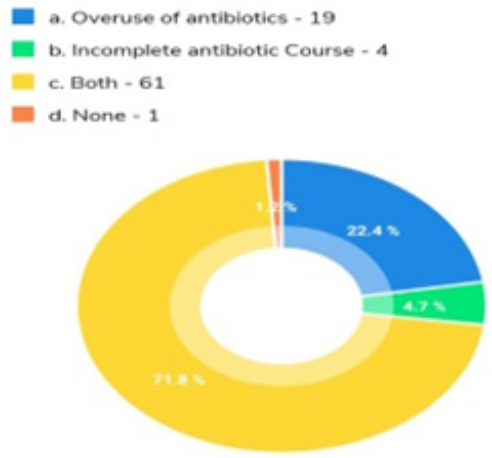

Figure 8: Do you know the cause of antibiotic resistance?
9. 9. Do you know about prevention of antibiotic resistance?

PIE CHART

$$
\begin{aligned}
& \text { - } 2 \text { Yคs }-48 \\
& \text { - b. No- } 16 \\
& \text { [1] Not sure - } 22
\end{aligned}
$$

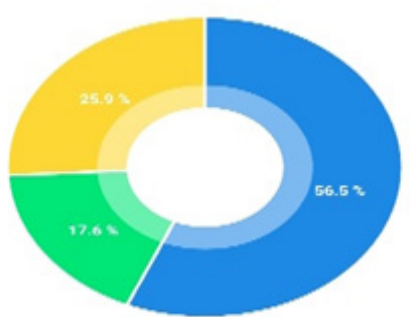

Figure 9: Do you know about prevention of antibiotic resistance?

10. 10. Do you about the side
effects of excess antibiotic
consumption?

PIE CHART

$$
\begin{aligned}
& \text { a. Yes }-42 \\
& \text { b. No }-14 \\
& \text { c. Not sure - } 29
\end{aligned}
$$

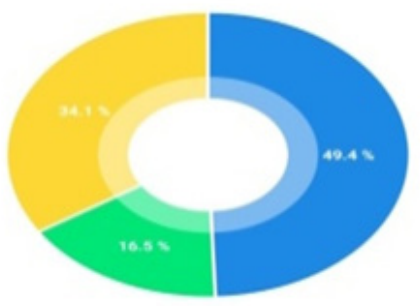

Figure 10: Do you know about the side effects of excess antibiotic consumption?

\section{11. Would you like to attend any seminar based on awareness about antibiotics and it's resistance?}

\section{PIE CHART}
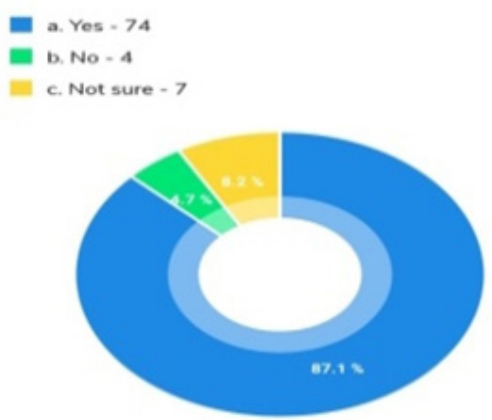

Figure 11: Would you like to attend any seminar based on awareness about antibiotics and it's resistance? 


\section{Discussion}

Indiscriminate use of antibiotics or incompletion of prescribed antibiotic dose are the reason for antibiotic resistance. Incorrectly prescribed antibiotics have questionable therapeutic benefit and expose patients to potential complications of antibiotic therapy $[5,6]$. Changes in antibiotic-induced gene expression can increase virulence, while increased mutagenesis and Horizontal gene transfer promote antibiotic resistance and spread [7-9].

In this study, 78.8\% student knew about antibiotics by definition which is similar to other studies [10]. Study done by Shivanni [11] suggested that $53 \%$ students used antibiotics for the next time by using previous prescription but in present study this percentage is less (36.5\%). 43.5\% consumed antibiotics without prescription which is similar to the other studies done by various authors, it could be because many of them were unsure about the side effects of the excess antibiotic consumption $[4,5,9,10]$. (Figure 3 ). In this study $71.8 \%$ completed the prescribed antibiotics dose which is in accordance with study done by Shivanni [11] and higher than some other studies $[4,5,9,10] .36 .9 \%$ students stopped consuming antibiotics once the symptoms subsided (Figure 5). Only $22.4 \%$ students think that antibiotics can be taken during viral infection (Figure 6).

A study was conducted in Chennai among dental students to check knowledge and awareness about antibiotic resistance usage and emerging drug resistance bacteria where it was found that $62 \%$ of people are aware about the method of controlling antibiotic resistance whereas in this study $94.1 \%$ knew about antibiotic resistance. In this study $71.8 \%$ students knew the cause of developing antibiotic resistance (Figure 8).

A similar study done, to know about knowledge, awareness and prevention of antibiotic resistance and causes among dental students of Saveetha Dental College, where it was found that $74 \%$ of the students knew the importance of prevention of antibiotic resistance, $52 \%$ knew about the consequences of antibiotic resistance [10]. In this study the percentage of prevention of antibiotic resistance and side effects of antibiotic consumption are respectively $56.5 \%$ (Figure 9) and $49.4 \%$ (Figure 10) which is on lower side. Major percentage of students (87.1\%) showed willingness to attend a seminar so as to increase awareness about antibiotic resistance.

In our study, majority of the students knew about correct definition of antibiotics, about antibiotic resistance and its causes. They also knew about prevention of antibiotic resistance, but a significant percentage of students did not apply their knowledge when using antibiotics and many of them were unsure about the side effects of excess antibiotic consumption.

\section{Conclusion}

Major percentage of students had good knowledge about antibiotic and antibiotic resistance but, Many of them consumed antibiotics without prescription and used previous prescription to take antibiotics and many of times did not complete the of prescribed antibiotic dose may be the reason for resistance. Thus, it is required that the students must be educated about consumption of antibiotics so as to prevent antibiotic resistance. Sensitization should be done through educational interventions. Awareness among students will be created by conducting CMEs, and workshops on regular basis. Since the present study involved only Final year dental students, further research can be undertaken to assess and compare the knowledge of postgraduate dental students on antibiotics.

\section{Conflicts of Interests:}

Nil.

\section{References}

1. (2013) The antibiotic alarm. Nature 495(7440): 141.

2. Read AF, Woods RJ (2014) Antibiotic resistance management. Evol Med Public Health 2014(1): 147.

3. Verma RK, Mohan L, Pandey M (2010) Evaluation of self-medication among professional students in North India: Proper statutory drug control must be implemented. Asian J Pharm Clin Res 3(1): 60-64.

4. Punj A, Shenoy SB, Thomas B, Ramesh A (2016) Knowledge awareness and prescription practice of antibiotics among private dental practitioners in Mangalore. J Educ Ethics Dent 6: 72-77.

5. Shaik T, Meher BR (2017) A questionnaire-based study to assess the knowledge, attitude and practice (KAP) of rationale use of antibiotics among undergraduate dental students in a tertiary care dental hospital of South India. International Journal of Basic \& Clinical Pharmacology $6(2)$.

6. Cope AL, Francis NA, Wood F, Chestnutt IG (2016) Antibiotic prescription in UK general dental practices: A cross sectional study. Community Dent Oral Epidemiol 44(2): 145-153.

7. Lushniak BD (2014) Antibiotic resistance: a public health crisis. Public Health Rep 129(4): 314-316.

8. Vishwanathan VK (2014) Off-label abuse of antibiotic by bacteria. Gut Microbes 5(1): 3-4.

9. Agarwal S, Yewale VN, Dharmapalan D (2015) Antibiotics use and misuse in children: A knowledge, attitude and practice survey of parents in India. J Clin Diagn Res 9(11): SC21-SC24.

10. Pushpaanjali G, Geetha RV, Lakshmi T (2020) Knowledge and awareness about antibiotic usage and emerging drug resistance bacteria among dental students. JPRI 32(16): 34-42.

11. Shivanni SS, Anita Roy (2017) Knowledge and awareness of antibiotic resistance among dental students. International Journal of Science and Research (IJSR) 6(4): 1343-1345. 